\title{
Heterogeneous strain regime in the eastern margin of Tibetan Plateau and its tectonic implications
}

\author{
Guojie Meng $\cdot$ Xiaoning Su $\cdot$ Weiwei Wu $\cdot$ \\ Jinwei Ren · Yonglin Yang • Jicang Wu • \\ Chieh-Hung Chen $\cdot$ Nikolay V. Shestakov
}

Received: 15 September 2014/ Accepted: 18 December 2014/Published online: 10 February 2015

(C) The Author(s) 2015. This article is published with open access at Springerlink.com

\begin{abstract}
The eastern margin of Tibetan Plateau is one of the most active zones of tectonic deformation and seismicity in China. To monitor strain buildup and benefit seismic risk assessment, we constructed 14 survey-mode global position system (GPS) stations throughout the northwest of Longmenshan fault. A new GPS field over 1999-2011 is derived from measurements of the newly built and pre-existing stations in this region. Sequentially, two strain rate fields, one preceding and the other following the $2008 M_{\mathrm{W}} 7.9$ Wenchuan earthquake, are obtained using the Gausian weighting approach. Strain field over 1999-2007 shows distinct strain partitioning prior to the $2008 M_{\mathrm{W}} 7.9$ Wenchuan earthquake, with compression spreading over around Longmenshan area. Strain field
\end{abstract}

\section{G. Meng $(\varangle)$}

Division of Earthquake Deformation, Institute of Earthquake

Science, China Earthquake Administration, Beijing, China

e-mail: guojiemeng@126.com

G. Meng $\cdot$ X. Su $\cdot$ W. Wu $\cdot$ J. Ren

Key Laboratory of Earthquake Prediction, Institute of

Earthquake Science, China Earthquake Administration, Beijing,

China

Y. Yang

Engineering Institute of Surveying and Mapping, Earthquake

Administration of Sichuan Province, Ya'an, China

J. Wu

Tongji University, Shanghai, China

C.-H. Chen

"National" Chung Cheng University, Chiayi, Taiwan

N. V. Shestakov

Institute of Applied Mathematics, Far Eastern Branch of Russian

Academy of Sciences, Vladivostok, Russia derived from the two measurements in 2009 and 2011 shows that the area around Longmenshan continues to be under striking compression, as the pattern preceding the Wenchuan earthquake, implying a causative factor of the sequent of $2013 M_{\mathrm{W}} 6.7$ Lushan earthquake. Our GPSderived dilatation shows that both the Wenchuan and Lushan earthquakes occurred within the domain of pronounced contraction. The GPS velocities demonstrate that the Longriba fault underwent slight motion with the faultnormal and -parallel rates at $1.0 \pm 2.5 \mathrm{~mm}$ and $0.3 \pm 2.2 \mathrm{~mm} / \mathrm{a}$; the Longmenshan fault displayed slow activity, with a fault-normal rate at $0.8 \pm 2.5 \mathrm{~mm} / \mathrm{a}$, and a fault-parallel rate at $1.8 \pm 1.7 \mathrm{~mm} / \mathrm{a}$. Longriba fault is on a par with Longmenshan fault in strain partitioning to accommodate the southeastward motion of eastern margin of the Tibetan Plateau. Integrated analysis of principal strain tensors, mean principal stress, and fast directions of mantle anisotropy shows that west of Sichuan is characterized as mechanically strong crust-mantle coupling.

Keywords GPS measurement · Longmenshan fault zone $\cdot$ Longriba fault zone $\cdot$ Tectonic deformation · Tibetan Plateau

\section{Introduction}

The eastern margin of the Tibetan Plateau, located in the broadest and most active area of intra-continental deformation in the world, is tectonically and seismically active. Several major active faults, such as the Xianshuihe, Aninghe, and Zemuhe faults, are presented here (Fig. 1). Historically more than 12 strong earthquakes, with $M>7.0$, have occurred in this region. In order to study the crustal deformation and its process, global position system 


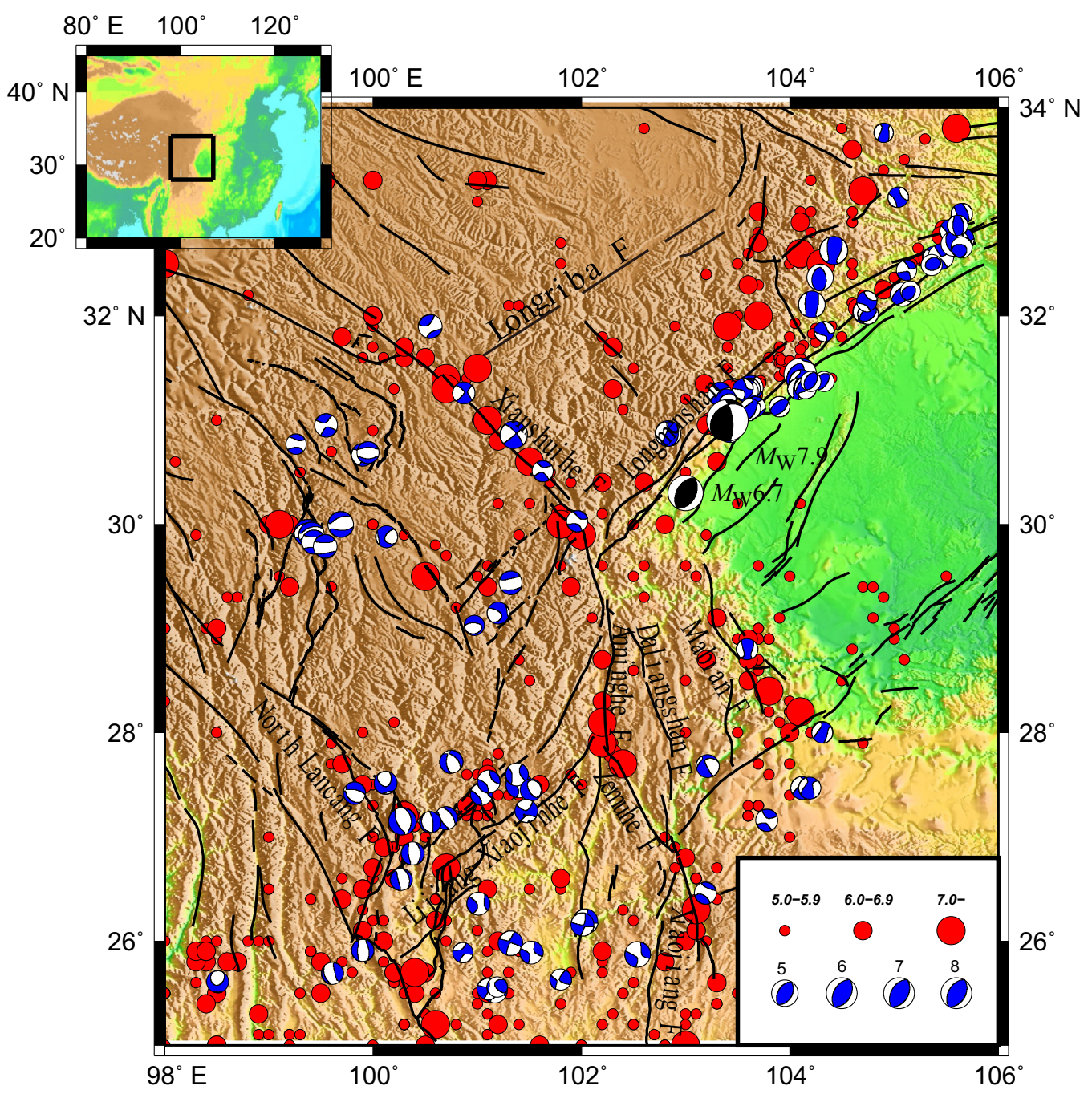

Fig. 1 Tectonic configure of the western Sichuan region (after Wang et al. 1998; Deng et al. 2003). The inset map on the upper left shows the study area. Red dots are earthquakes with magnitude equal or greater than 5.0 from 780 BC to 2007 (China Earthquake Networks Center catalogue). The focal mechanisms for $M_{\mathrm{W}}>5.0$ earthquake occurring in the period of 1 August 1976 to 3 March 2013 are from the Global Centroid Tensor (GCMT) catalogue (available at http://www.globalcmt.org/CMTsearch.html, last accessed July 2014). The two black and white beach balls (Luo, personal communication, 2014) represent the focal mechanisms of the 12 May $2008 M_{\mathrm{W}} 8.0$ Wenchuan and the 20 April 2013 Lushan $M_{\mathrm{W}} 6.7$ earthquakes, respectively. $D L S F$. Daliangshan fault; ZMH F. Zemuhe fault; ANH F. Anninghe fault

(GPS) stations were established throughout this region and results were obtained by several groups (e.g., King et al. 1997; Chen et al. 2000; Shen et al. 2005; Gan et al. 2007; Meng et al. 2008; Liang et al. 2013). Wang et al. (2001) identified that the region south of Ganzi-Mani fault moves eastward relative to both Indian and Eurasian plates. Strain rates derived from sparse GPS sites using Delaunay triangle approach are significant at the $95 \%$ and $99 \%$ confidence level in the eastern borderland of Tibetan Plateau (Calais et al. 2006). Although crustal deformation in this area has been studied and characterized previously, some unresolved arguments still need to be addressed, e.g., what is the linkage among surficial deformation and stress regime in the crust and mantle deformation? (Lev et al.
2006). In this paper, we have collected GPS data of Crustal Movement Observation Network of China (CMONOC) and its successor the Continental Tectonic Environmental Monitoring Network of China over 1999-2011. Moreover, 14 survey-mode GPS sites were established after the 2008 $M_{\mathrm{W}} 7.9$ Wenchuan earthquake and surveyed five times during 2009-2011. These GPS measurements allow us to derive a denser velocity field in eastern Tibetan Plateau, especially in the northwestern Longmenshan area. A new strain rate field is sequentially computed using the Gaussian weighing approach to examine the strain buildup, and its implications for stress regime and tectonic evolution in the framework of eastern movement of crust in response to the collision between the Eurasian and Indian plates. 


\section{Seismotectonic setting}

The present-day tectonic framework of the eastern Tibetan Plateau (Fig. 1) is the result of geodynamic processes related to the Indo-Eurasian convergence some 50 Myr ago (Wang and Burchfiel 2000; Wang et al. 2014a, b). The eastern margin is partitioned by a network of active faults (Fig. 1), among which the Xianshuihe fault is most active (Allen et al. 1991). The slip rate of the Xianshuihe fault since the Quaternary is about $8-15 \mathrm{~mm} / \mathrm{a}$ (Deng et al. 1994; Xu et al. 2003). Several large earthquakes have occurred along these major fault systems historically, with $M \geq 7$ events took place mainly along active faults (Deng et al. 1994). A series of large earthquakes occurred along the Xianshuihe fault, in particular on the Luohuo-Daofu segment: the 1816 earthquake of $M 7.5$, the 1893 earthquake of $M 7$, the 1923 earthquake of M7.3, and the 1981 earthquake of $M_{\mathrm{W}} 7.0$ (Su and Qin 2001; Yang et al. 2005). The Longmenshan fault frequently ruptured in small to moderate size earthquakes prior to the 2008 Wenchan $M_{\mathrm{W}} 7.9$ and 2013 Lushan $M_{\mathrm{W}} 6.7$ event. Historically a couple of earthquakes with magnitudes around 6 occurred within $50-150 \mathrm{~km}$ of this fault, such as 1,657 M6.5 Wenchuan and $1970 M_{\mathrm{S}} 6.2$ Dayi earthquakes (Division of Earthquake Monitoring and Prediction 1995, 1999). No earthquakes with $M \geq 7$ had been documented along this fault prior to the $2008 M_{\mathrm{W}} 7.9$ Wechuan seismic event. The devastating 2013 Lushan earthquake ruptured the southwestern part of the Longmenshan fault on 20 April 2013, with its epicenter close to the Lushan county, causing 193 deaths and injuring over 10,000 people. The Lushan earthquake is the largest event in the years following the 12 May $2008 M_{\mathrm{W}} 7.9$ Wenchuan earthquake. The epicenters of the two destructive earthquakes are $87 \mathrm{~km}$ apart from each other along the Longmenshan fault. Previous GPS measurements show that the northeast-striking Longmenshan fault has undergone slight shortening with contraction rates of 1.1 and $2.4 \mathrm{~mm} / \mathrm{a}$ for the southwestern and northeastern segments before the $2008 M_{\mathrm{W}} 7.9$ Wenchuan earthquake (Meng et al. 2008; Zhang et al. 2010). The focal mechanisms of contemporary earthquakes in this region reveal a NNE horizontal maximum compressive stress (Kan et al. 1977; $\mathrm{Xu}$ et al. 1989). Seismic velocity models indicate that the crustal thicknesses of the western Sichuan plateau and the Sichuan basin are 62 and $43 \mathrm{~km}$, with lower crustal thicknesses at 27 and $15 \mathrm{~km}$, respectively (Wang et al. 2002). Therefore, the top surface of upper mantle displays great fluctuation in this region (Wang et al. 2002). Density models constructed from the seismic velocity models are consistent with observed Bouguer gravity anomalies (Wang et al. 2007).

\section{Methodology}

\subsection{GPS measurements and data processing}

GPS measurements have been conducted in eastern margin of Tibetan Plateau since 1999, when CMONOC was initiated then, and its successor CTEMN commenced to operate in 2010. Most stations were occupied regularly every 2 years. Under the financial support of National Basic and Key Project (973 Project) of 2008 Wenchuan Earthquake and Its Regional Dynamic Environment, we established 14 campaign GPS stations throughout west of Longmenshan fault in 2009, which are mounted with reinforced concrete pillars into bedrocks or sediments, as shown in Table 1. All these stations were occupied five epochs in the period of 2009-2011. Receivers and antenna used for each epoch are tabulated as given in Table 2.

The GPS data are processed using GAMIT/GLOBK software (King and Bock 2010; Herring et al. 2010) to derive time series of the station coordinates in the ITRF2008 reference frame. Regional station co-ordinates, 11 tropospheric zenith delay parameters per site per day, and phase ambiguities are solved for single-day solutions. IGS final orbits and IERS Earth Orientation Parameters are used, and elevation-dependent absolute antenna phase center corrections are made, following the tables recommended by the IGS08. The loosely constrained solutions from our processing were combined with the loosely constrained solutions of 16 international global navigation satellite systems (GNSS) service (IGS) stations, the data for which are available from the Scripps Orbital and Positioning Analysis Center. The least squares adjustment vector and the variance-co-variance matrix for station positions and orbital elements estimated for each independent daily solution are then combined with global H-files from Scripps Institution of Oceanography (SIO). Common parameters in all solutions, such as the satellite orbit, polar motions, and tracking station positions, are solved with loose constraints on all the parameters. In the final step, station positions and velocities are estimated with the QOCA software (Dong et al. 1998) through sequential Kalman filtering, allowing adjustment for global translation and rotation of each daily solution. We impose the reference frame by minimizing the position and velocity deviations of $\sim 40$ IGS core stations with respect to the ITRF2008 (Altamimi et al. 2011) while estimating the orientation, translation, and scale transformation parameters. Random walk perturbations are allowed for the parameters whose errors are correlated with time. The height coordinates and vertical velocities are weighted by a factor of 10 less than the horizontal components. The 
Table 1 Description of the GPS stations of the 973 Project: $\mathrm{RCP}$, reinforced concrete pillar

\begin{tabular}{llllll}
\hline No. & Site & Long. $\left({ }^{\circ} \mathrm{E}\right)$ & Lat. $\left({ }^{\circ} \mathrm{N}\right)$ & Height $(\mathrm{m})$ & Monument type \\
\hline 1 & EP01 & 105.525 & 32.6502 & 704 & RCP deepened into sediments \\
2 & EP02 & 105.476 & 32.7452 & 775 & RCP deepened into bedrock \\
3 & EP03 & 105.438 & 32.8067 & 763 & RCP deepened into bedrock \\
4 & EP04 & 105.698 & 33.6683 & 1,498 & RCP deepened into bedrock \\
5 & EP05 & 105.695 & 33.7678 & 1,116 & RCP deepened into sediments \\
6 & EP06 & 105.270 & 34.2446 & 1,467 & RCP deepened into sediments \\
7 & WP01 & 104.221 & 32.5461 & 1,450 & RCP deepened into sediments \\
8 & WP02 & 104.059 & 32.5258 & 1,540 & RCP deepened into sediments \\
9 & WP03 & 103.698 & 32.7391 & 3,889 & RCP deepened into bedrock \\
10 & WP04 & 103.563 & 32.839 & 3,182 & RCP deepened into bedrock \\
11 & WP05 & 103.716 & 33.0692 & 3,279 & RCP deepened into sediments \\
12 & WP06 & 104.737 & 33.2407 & 2,113 & RCP deepened into sediments \\
13 & WP07 & 104.344 & 33.5777 & 2,188 & RCP deepened into sediments \\
14 & WP08 & 104.499 & 33.6314 & 1,450 & RCP deepened into bedrock \\
\hline
\end{tabular}

Table 2 Occupation history for the 973 Project sites $^{\mathrm{a}}$

\begin{tabular}{|c|c|c|c|c|c|}
\hline Site & $2009.87^{\mathrm{b}}$ & $2010.24^{\mathrm{b}}$ & $2010.75^{\mathrm{b}}$ & $2011.12^{\mathrm{b}}$ & $2011.41^{\mathrm{b}}$ \\
\hline EP01 & TRIMBLE 5700 & TPS NET-G3A & LEICA GRX1200 PRO & LEICA GRX1200 PRO & LEICA GRX1200 PRO \\
\hline EP02 & TRIMBLE 5700 & TPS NET-G3A & Trimble NetR8 & Trimble NetR8 & Trimble NetR8 \\
\hline EP03 & TRIMBLE 5700 & TPS NET-G3A & Trimble NetR8 & Trimble NetR8 & Trimble NetR8 \\
\hline EP04 & TRIMBLE 5700 & TPS NET-G3A & LEICA GRX1200 PRO & LEICA GRX1200 PRO & Trimble NetR8 \\
\hline EP05 & TRIMBLE 5700 & TPS NET-G3A & Trimble NetR8 & Trimble NetR8 & LEICA GRX1200 PRO \\
\hline EP06 & TRIMBLE 5700 & TRIMBLE NetR8 & Trimble NetR8 & Trimble NetR8 & Trimble NetR8 \\
\hline WP01 & TRIMBLE 5700 & TPS NET-G3A & TPS NET-G3A & TPS NET-G3A & TPS NET-G3A \\
\hline WP02 & TRIMBLE 5700 & TPS NET-G3A & TPS NET-G3A & TPS NET-G3A & TPS NET-G3A \\
\hline WP03 & TRIMBLE 5700 & TPS NET-G3A & TPS NET-G3A & TPS NET-G3A & TPS NET-G3A \\
\hline WP04 & TRIMBLE 5700 & TPS NET-G3A & TRIMBLE 5700 & TPS NET-G3A & TPS NET-G3A \\
\hline WP05 & TRIMBLE 5700 & TPS NET-G3A & TPS NET-G3A & TPS NET-G3A & TPS NET-G3A \\
\hline WP06 & TRIMBLE 5700 & TRIMBLE NetR8 & TPS NET-G3A & Trimble NetR8 & LEICA GRX1200 PRO \\
\hline WP07 & TRIMBLE 5700 & TRIMBLE NetRS & TPS NET-G3A & TPS NET-G3A & TPS NET-G3A \\
\hline WP08 & TRIMBLE 5700 & TRIMBLE NetRS & TPS NET-G3A & TPS NET-G3A & TPS NET-G3A \\
\hline
\end{tabular}

${ }^{a}$ GPS receiver used

b Here columns 2009.87-2011.41 refer to occupation time epochs; 2009.87 means year 2009.87, which is around November 15 th in 2009

velocity solution was transformed into the Eurasia-fixed reference frame using the Euler vector of Eurasia with respect to the ITRF2008. In fitting the site coordination time series to derive long-term, linear velocities, a weighted least square approach is employed. The site velocity uncertainties are scaled on a component by component basis in the light of goodness of fit to the linear models.

Significant coseismic offsets and post-seismic deformation caused by the $2008 M_{\mathrm{W}} 7.9$ Wenchuan earthquake were identified within the Sichuan Basin and the west of the Longmenshan fault (Shen et al. 2009; Wang et al. 2011). Therefore, removal of the effect of the Wenchuan earthquake on site velocities is prerequisite in deriving reliable site velocities. The inclusion of data of occupation in 2009 following the Wenchuan earthquake has been tested to check its effect on the linear site velocities in two steps. First, the times series of each given component is fitted for the time span of 1999-2011 by the least squares regression. Second, site velocities are computed again with the data of survey in 2009 excluded. If the second estimate significantly exceeds the intervals of the $90 \%$ confidence level constructed by using the entire data (i.e., from 1999 to 2011), it indicates that post-seismic deformation of the Wenchuan earthquake can significantly bias the long-term, linear velocities. Thus, the second estimate of linear 
velocities is considered to be the long-term motion. Otherwise, the estimated value for the whole time span is thought to be the velocity of the given component.

\subsection{Strain rate computation}

We compute the velocity gradient tensor over a $0.5^{\circ} \times 0.5^{\circ}$ grid, following a least squares solution, using the velocity field from GPS surveys. The GPS velocity at a given point can be written as

$u_{i}=t_{i}+\frac{\partial u_{i}}{\partial x_{j}} x_{j}=t_{i}+\boldsymbol{e}_{i j} x_{j}$,

where indexes $i$ and $j$ correspond to spatial coordinates, $t_{i}$ is the velocity with respect to the grid point, $\boldsymbol{e}_{i j}$ is the velocity gradient tensor, $u_{i}$ is the individual GPS velocities, and $\Delta x_{j}$ is the baseline between each station and the grid point (Shen et al. 1996; Allmendinger et al. 2007; Crowell et al. 2013). The following inverse problem is set up to solve for the velocity gradient tensor

$$
\begin{aligned}
\boldsymbol{u} & =\left[\begin{array}{c}
u_{x}^{1} \\
u_{y}^{1} \\
\vdots \\
u_{x}^{n} \\
u_{y}^{n}
\end{array}\right]=\boldsymbol{G l} \\
& =\left[\begin{array}{cccccc}
1 & 0 & \Delta_{x 1} & \Delta_{y 1} & 0 & 0 \\
0 & 1 & 0 & 0 & \Delta_{x 1} & \Delta_{y 1} \\
& & & & \vdots & \\
1 & 0 & \Delta_{x n} & \Delta_{y n} & 0 & 0 \\
0 & 1 & 0 & 0 & \Delta_{x n} & \Delta_{y n}
\end{array}\right]\left[\begin{array}{c}
t_{x} \\
t_{y} \\
e_{x x} \\
e_{x y} \\
e_{y y} \\
e_{y x}
\end{array}\right],
\end{aligned}
$$

where $G$ is the design matrix, $l$ is a vector containing the velocity gradient and translation terms, and $n$ is the number of GPS sites. We employ a weighted least square inversion using station velocities and their co-variances to solve for strain rate components through

$l=\left(\boldsymbol{G}^{\mathrm{T}} W \boldsymbol{G}\right)^{-1} \boldsymbol{G}^{\mathrm{T}} W u$,

where $W$ is weighting factor calculated by a Gausian window

$W=C_{i j} \exp \left(\frac{-d^{2}}{\alpha^{2}}\right)$,

where $C_{i j}$ is the velocity co-variance of site $i$ and $j, \alpha$ is a distance-decaying constant, and $d$ is the distance between the grid point and the station. For example, $\alpha=150 \mathrm{~km}$ corresponds to a spatial smoothing by a Gaussian window with one standard deviation of $150 \mathrm{~km}$ centered at the point where strain rate is estimated. This window weighs data $50 \%$ for sites $125 \mathrm{~km}$ from the center. For $\alpha=90 \mathrm{~km}$, distance of $50 \%$ weighting is decreased to $75 \mathrm{~km}$.

\section{Results and analyses}

\subsection{Characteristics of GPS velocity field}

Figure 2 shows the resultant horizontal velocities for the GPS eastern margins of Tibetan Plateau relative to stable Eurasian plate over the period of 1999-2011. The GPS sites west of Sichuan exhibit southeast-directed movement. The GPS sites within the area of $102^{\circ} \mathrm{E}-104^{\circ} \mathrm{E}, 35^{\circ} \mathrm{N}-$ $37^{\circ} \mathrm{N}$, to the northwest of Ordos block, are characterized by northeastern movement. West of Ordos block is found to move southeastward, showing a striking clockwise rotation, in agreement with previous measurements (Gan et al. 2007). This result suggests that the transition of northeastern motion is attributed to the obstruction of the relatively rigid Ordos block. Our GPS velocity field illustrates the known southeastern motion of the crust around the Longmenshan fault area (Shen et al. 2005; Liang et al. 2013). Horizontal velocities show an obvious decrease eastward (around $22 \mathrm{~mm} / \mathrm{a}$ in the west, decreasing to less than $7.0 \mathrm{~mm} / \mathrm{a}$ in the east). The velocities of GPS sites in the domain confined by the Xianshuihe and Longmenshan faults show a pattern of southeastward motion with velocity decreasing in this direction. The velocity decreases for GPS sites from the Longriba fault to the Longmenshan fault suggests crustal strain could be accumulating in this zone. To the south of intersection of Longmenshan and Xianhuihe faults, GPS sites move southward compared to those west of Longmenshan fault, indicative of a known clockwise rotation here (Shen et al. 2005). It should be noted that the 14 newly built GPS sites have relatively larger uncertainties due to their shorter span of observations, as shown in Fig. 3.

\subsection{Strain rates distribution}

We use $\alpha=150 \mathrm{~km}$, which is the average distance of the closest station to each grid point with a size of $0.5^{\circ} \times 0.5^{\circ}$. To identify known strain accumulation before and after the 2008 great Wenchuan earthquake, and to determine strain pattern prior to the $2013 M_{\mathrm{W}} 6.7$ Lushan earthquake, we have calculated strain rate tensor with its uncertainties for the periods of 1999-2007 and 2009-2011.

Prior to the $2008 M_{\mathrm{W}} 7.9$ Wenchuan earthquake, within the area around the Xianshuihe Fault system and the Longmenshan fault, principal strain rates showed a combination of WNW-ESE compression and NNE-SSW extension, whereas strain rates, west of Longriba fault are relatively smaller with a ENE-WSW contraction and a NNW-SSE extension. Northeastern segment of Longmenshan fault exhibits a pronouncedly different strain pattern, with compressional maximum principal strain toward EW direction, and negligible extensional principal 

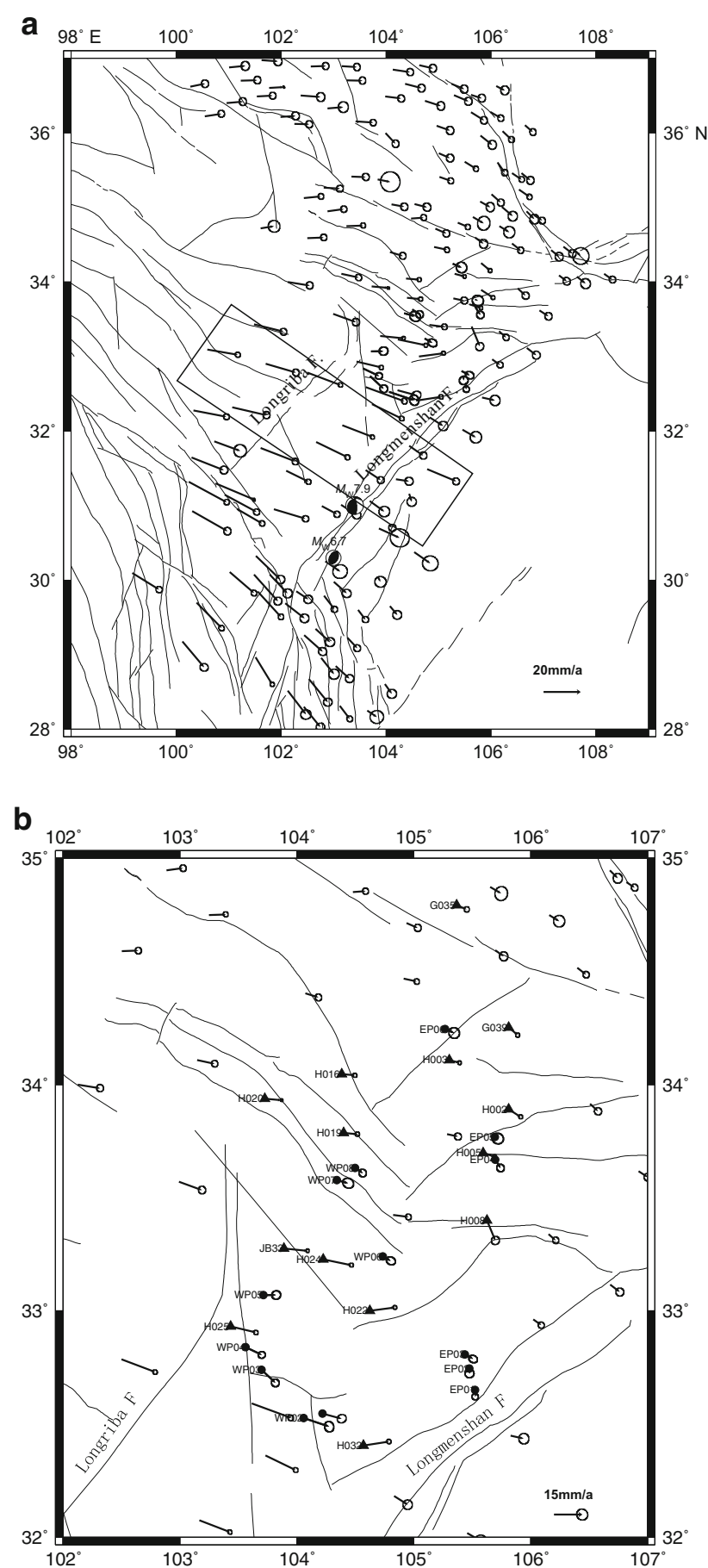

Fig. 2 a GPS velocities with respect to the stable Eurasian plate. Error ellipses show with $95 \%$ confidence level. b Velocities of the 973 Project sites and pre-existing sites resurveyed in 2009-2011. Solid circles are the 973 Project sites; black triangles are stations of CMONOC or CTEMN, resurveyed synchronously with 973 Project sites. The other sites are pre-existing GPS sites

strain component in the NS direction. Dilation rate distribution demonstrates a widespread compression around western Sichuan Basin up to the Longriba fault northwestward, with maximum value at $3.6 \times 10^{-8} / \mathrm{a}$.
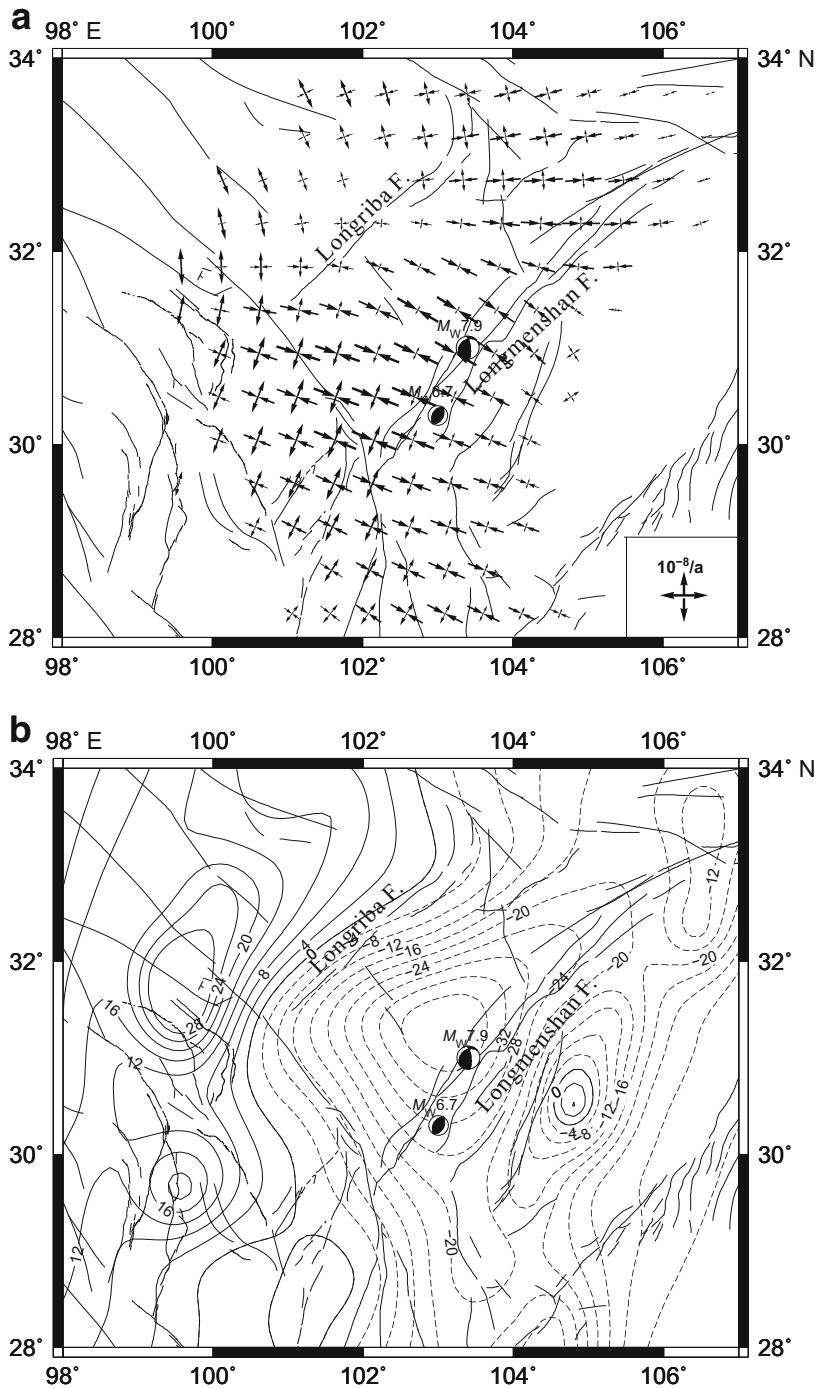

Fig. 3 Principal strain rate (a) and dilation rate (b) over 1999-2007. The two beach balls represent the mechanisms of the 12 May 2008 Wenchuan $M_{\mathrm{W}} 7.9$ and the 20 April 2013 Lushan $M_{\mathrm{W}} 6.7$ earthquakes, respectively

Nevertheless, the western portion of the Xianshuihe fault exists localized extension that would be the edge effect of the strain calculation, due to the sparse GPS sites in this area.

Principal strain rate, shown in Fig. 4a, calculated from the two observation epochs in 2009 and 2011 shows that the strain regime is generally the same as that derived from observations in the interval of 1999-2007. But both principal compression and extensional strain components present relatively larger values, indicating that the 2008 $M_{\mathrm{W}} 7.9$ Wenchuan earthquake did not cause an immense effect on the style of crust deformation. However, a faster local strain change can be seen in Fig. $4 \mathrm{~b}$, in agreement with other researches claiming that the Wenchuan 

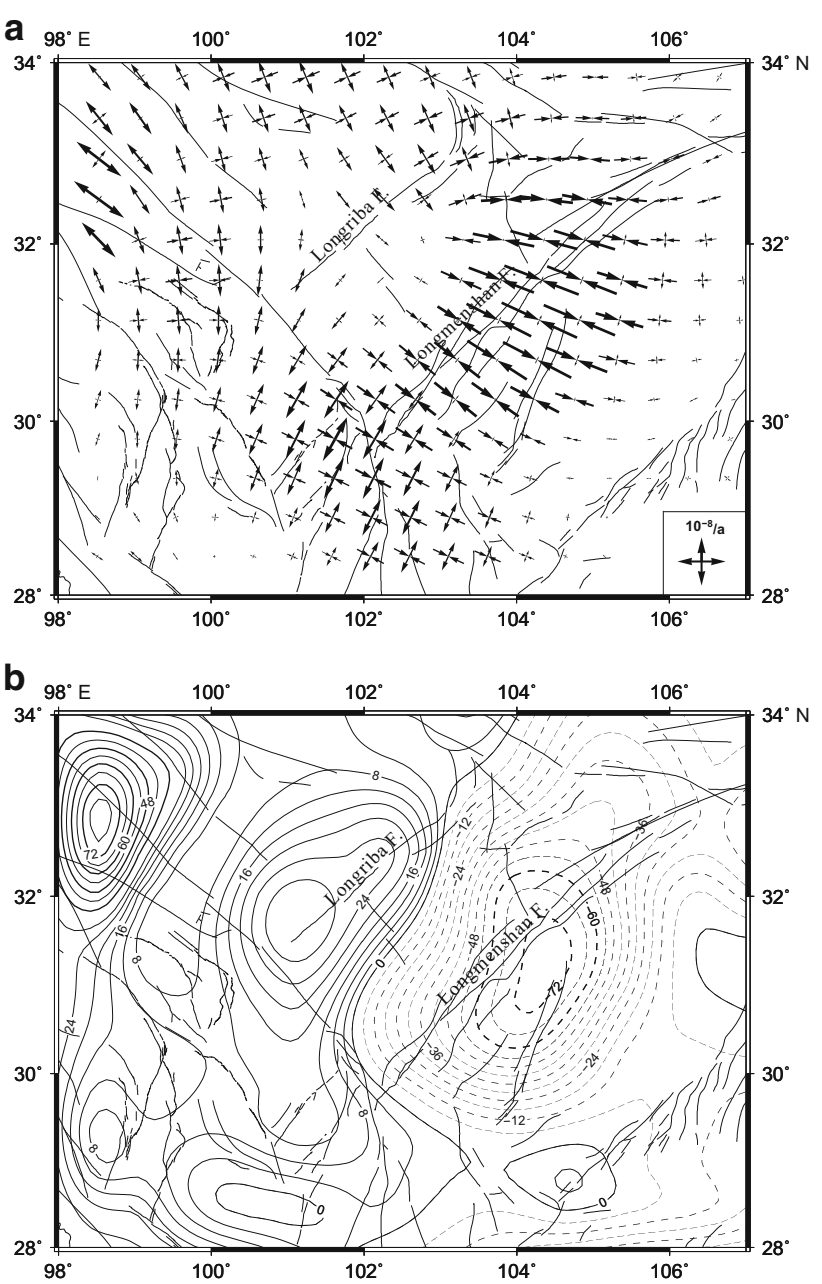

Fig. 4 Principal strain rate distribution (a) and dilation rate (b) over 2009-2011. Other items are the same as shown in Fig. 3

earthquake has facilitated the occurrence of the 2013 $M_{\mathrm{W}} 6.7$ Lushan earthquake (Liu et al. 2014; Wang et al. 2014b).

\section{Discussion}

\subsection{Strain partitioning}

The eastern margin of Tibetan Plateau shows SSE-directed movement in response to the collision between the Indian and Eurasian plates (Fig. 2). In the western Sichuan area, the north-trending Longmenshan and Longriba faults, both oriented northeast, are oblique to the crustal motion relative to the South China block, offering a typical example of strain-partitioning regime. To identify the respective roles of the two faults in strain partitioning, a GPS velocity profile is plotted to be perpendicular to and to cross the two faults. As shown in Fig. 5a, b, we find that the Longriba fault evidently undergoes insignificant motion with the
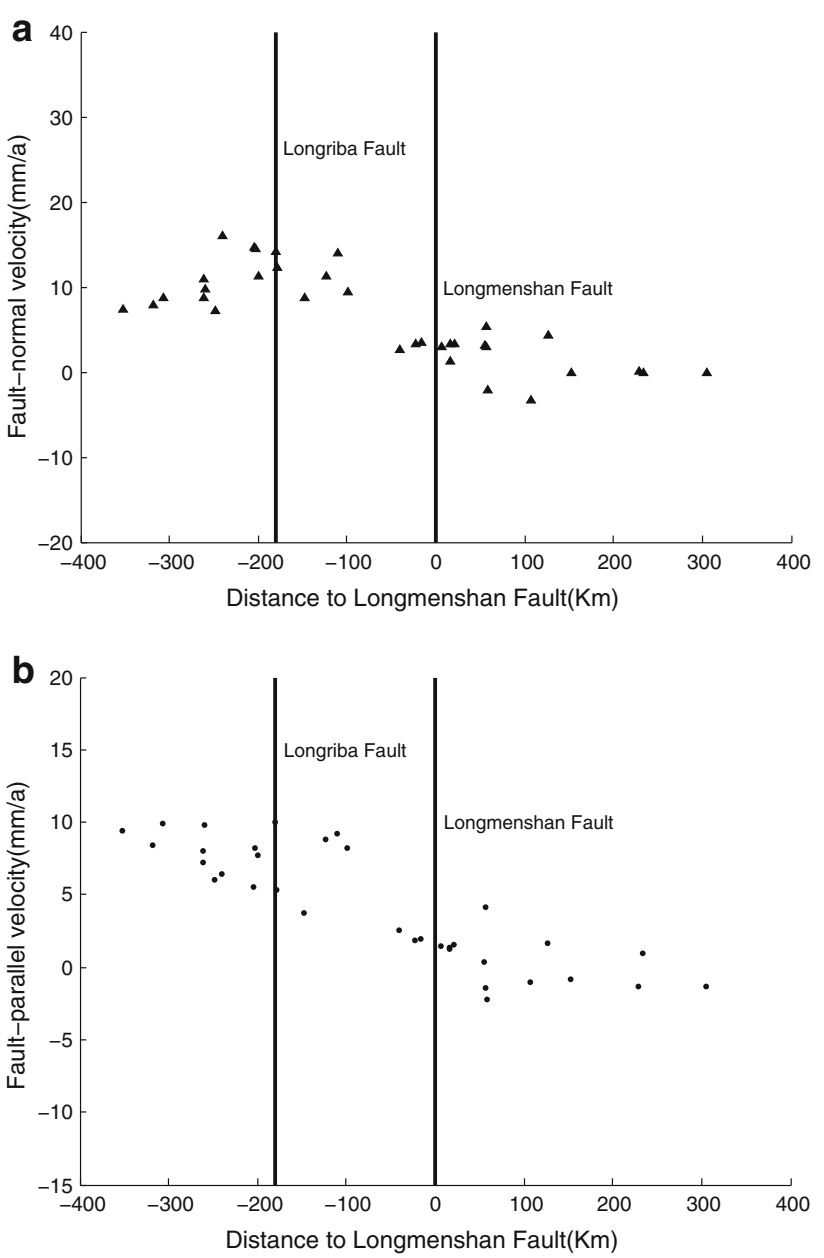

Fig. 5 Fault-parallel (a) and -normal (b) velocity profiles across the Longriba and Longmenshan faults zone. The velocities are with respect to the South China block. Location of the profile is shown in Fig. 2a

fault-normal and -parallel rates at $1.0 \pm 2.5 \mathrm{~mm}$ and $0.3 \pm 2.2 \mathrm{~mm} / \mathrm{a}$. This result is obviously different from Shen et al.'s (2005), due to the shorter length and narrower width of Longriba fault-crossing profile in this study, and only near-fault stations employed to calculate the activity of the Longriba fault. Longmenshan fault displayed slow activity, with a fault-normal rate at $0.8 \pm 2.5 \mathrm{~mm} / \mathrm{a}$, and a fault-parallel rate at $1.8 \pm 1.7 \mathrm{~mm} / \mathrm{a}$. This result contrasts with the geological solution of Ren et al.'s (2013) that the slip of the Longriba fault in the latest Pleistocene is up to $\sim 7.5 \mathrm{~mm} / \mathrm{a}$, indicating an apparent decrease of slip rate from the latest Pleisstocene to the Holocene. Using elastic subblocks model, Cheng et al. (2012) documented that Longriba fault is characterized by an evident dextral slip and negligible contraction; the difference likely results from their short spanning data and their modeling approach, which employed subblock motion to fit the velocities of GPS sites within respective subblocks. Du 
et al. (2009) found that Longriba fault underwent apparent creeping, sequently with a larger right-later slip of $4.7 \mathrm{~mm} /$ a and a contraction rate of $1.8 \mathrm{~mm} / \mathrm{a}$, exploiting a longer cross section across both Longriba and Longmenshan faults. The difference of our result in this paper from previous results is mostly due to different approaches and the lengths of cross section. As for profile approach, fault locking depth and plotted profile length should be balancedly taken into consideration. As pointed by Thatcher (2009), where data are sparse, structure is more complex, and block rotation is important, single profiles are often of limited use and may be misleading. There is a conspicuous drop in the fault-normal velocity between the Longriba and Longshan faults, corresponding to the southern segment of Minjiang fault. It seems that the Minjiang fault might is experiencing great compressure and dextral slip. Nevertheless, only 4 GPS site are located around the south part of the Minjiang fault, the big difference in GPS velocities need to be evaluated by more sites and longer observations. At this stage, we speculate that the Minjiang fault might play important role in strain partitioning in eastern Tibet. Therefore, denser geodetic stations and longer observations are quite necessary to better constrain the activities of the Longriba and Minjiang fault to infer their significance in identifying the strain-partitioning regime of eastern margin of the Tibetan Plateau.

\subsection{Implication for tectonics in eastern Tibet}

Mean regional stress field can be determined by focal mechanism solutions of shallow earthquakes, which reflects the stressing characteristics of the regional crust (Michael 1987; Xu et al. 1989). The mean stress tensors for 13 fault-bounded tectonic zones were derived from the focal mechanisms of 256 earthquakes with magnitudes larger than $M_{\mathrm{S}} 5.0$ (Zhong and Cheng 2006). Based on the mechanisms of $20 M>4.0$ earthquakes (Luo, personal communication, 2013), the tectonic stress in the focal zone was derived using linear stress inversion with bootstrapping (LSIB) of the destructive $2013 M_{\mathrm{W}} 6.7$ Lushan earthquake. The orientation of principal compressional axis is toward $125.2^{\circ}$, roughly perpendicular to the Longmenshan fault zone, indicating a compressional regime for the southern segment of this fault, consistent with the GPSderived strain rates. In this sense, the kinematic pattern could possess its intrinsic implication for dynamics process for crustal deformation.

The fast direction of seismic anisotropy determined using SKS splitting is a significant proxy of the deformation of upper mantle (Lev et al. 2006). Figure 6 shows the comparison among the GPS-derived principal strain tensors, the mean stress from compilation of previous researches, and the fast directions of seismic anisotropy. It can be seen that,

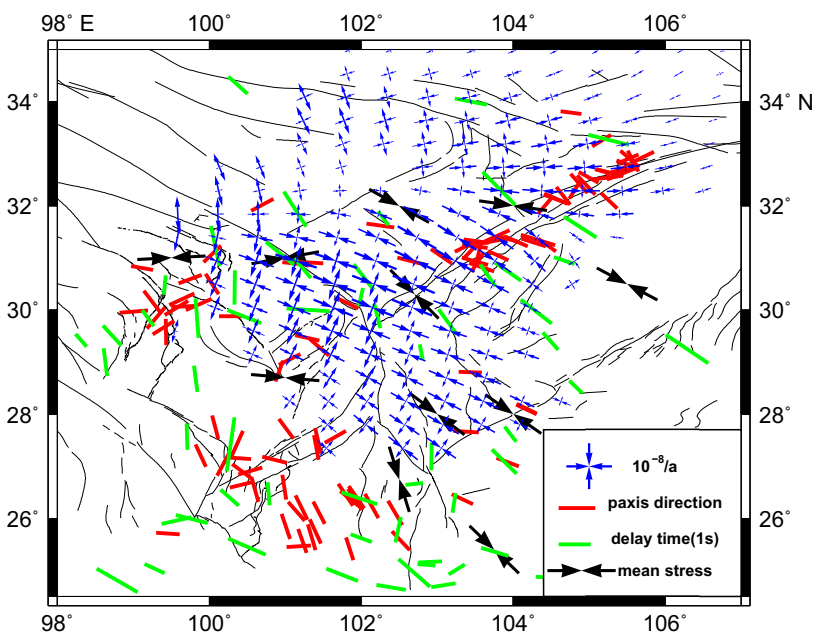

Fig. 6 Comparison of GPS-derived principal strains, the directions of mean compression stresses, and fast directions of mantle anisotropy (Lev et al. 2006; Sol et al. 2007). Mean compression stress axes are obtained from focal mechanism solutions for $M_{\mathrm{W}} \geq 5.0$ earthquakes and (Zhong and Cheng 2006). The gray lines represent active faults

within the area around the southern Longmenshan fault zone, the directions of maximum principal compression axes are in alignment with the mean stress directions. This result demonstrates that the seismic activity here correlates tightly with the horizontal strains, and GPS measurements in this region can be conducive to identify the stress regime in the crust.

The fast direction of seismic anisotropy is also consistent with surficial strain and mean stress. As is known that the anisotropy derived from SKS splitting mainly is a representative proxy of the deformation of upper mantle (Lev et al. 2006; Sol et al. 2007). Therefore, these observations suggest a coherent distributed lithospheric deformation beneath the southern portion of the Longmenshan fault zone. The deformation in the lithosphere should mechanically couple across the crust-mantle interface, and the lower crust is sufficiently strong to transit stress, rendering this area prone to accumulate tremendous strain energy to generate large earthquakes, evidenced by historical strong seismicity (Division of Earthquake Monitoring and Prediction, China Seismological Bureau 1999) and the recent Lushan $M_{\mathrm{W}} 6.7$ earthquake.

In the Xianshuihe fault zone, the directions of mean principal compression axes are not aligned with the principal minimum axes of GPS result, and at odds with the fast directions of anisotropy, indicating a complex deformation pattern in the crust and upper mantle. More insights are needed to identify the complex characteristic of lithospheric deformation in the zone. West of Sichuan Basin, GPSderived compressional principal axes are roughly accordant to the mean principal compressional axis, whereas the mantle anisotropy is not in accordant with GPS result and the mean 
compressional axes from focal mechanism solutions. This may indicate that the crust and upper mantle are, to slight degree, mechanically decoupled. Up to West Qinling fault zone, GPS-derived principal compression axes roughly agree with the fast direction of SKS splitting, implying that this area is characterized as mechanical coupling of crust-mantle.

In southwest of the Xianhuihe fault system, the fast directions of SKS splitting are clearly inconsistent with those of principal compression axes determined from focal mechanism solutions, indicative of a significant mechanical decoupling between the crust and upper mantle. It might be inferred that the lateral variation of crust-mantle coupling plays a mechanical role in tectonic evolution of eastern margin of the Tibetan Plateau.

\section{Conclusions}

A new GPS velocity field has been derived for the eastern flank of the Tibetan Plateau, with 14 newly built sites integrated, based on GPS measurements over the period of 1997-2011. The GPS velocities are generally, for common sites, in agreement with that of Liang et al. (2013), within an uncertainty of $2.0 \mathrm{~mm} / \mathrm{a}$. Yet our newly GPS sites play a more important role in constraining the crustal deformation of eastern margin of Bayan Har blocks, part of eastern Tibetan Platueau. Our result reveals that the GPS velocity field diverges around the intersection of Xianshuihe and Longmenshan faults, consistent with previous researches. This testifies that the eastern flow of materials from Tibet Plateau is resisted by the relatively rigid Sichuan Basin. The higher compressional strain prior to the $2008 M_{\mathrm{W}} 7.9$ Wenchuan earthquake is found to locate at the Longmenshan fault zone. Maximum principal compressional axes are roughly orthogonal to the Longmenshan fault zone at its southern segment, whereas at its northeastern portion, the principal compressional axes are nearly EW-directed, oblique to the strike of the Longmenshan fault, in agreement with the focal mechanism solutions of the large Wenchuan earthquake.

The strain pattern following the $2008 M_{\mathrm{W}} 7.9$ Wenchuan earthquake did not exhibit pronounced variation as compared to that prior to the destructive earthquake. This may suggest a continued rapid strain buildup in this area, which makes a significant contribution to the $2013 M_{\mathrm{W}} 6.7$ Lushan earthquake, occurring $\sim 100 \mathrm{~km}$ south-southwest of the epicenter of the $2008 M_{\mathrm{W}} 7.9$ Wenchuan earthquake. The GPS-derived principal compressional strain axes and the mean principal compressional stress ones from focal mechanism solutions are in agreement with the fast directions from mantle anisotropy at southwestern Longmenshan fault zone, indicating a strong mechanical coupling between the crust and upper mantle. At the southeastern segment of Xianshuihe fault, a complex pattern is identified for the lithospheric deformation. More intensified researches are needed to understand the causative factors, considering that at least six $M>7.0$ earthquakes ruptured the fault within the last 200 years.

Acknowledgments We are grateful to all colleagues who worked in the field to collect the GPS data used in this study. We thank 3 anonymous reviewers for their critical comments. This research was financially supported by the National Natural Science Foundation of China (Nos. 41174004, 41461164004, 41491240265), International Science \& Technology Collaborative Program of China (No. 2010DFB20190), the project of Far Eastern Federal University, Russia (14-08-01-05_m), State Key Basic Research Development and Programming Project of China (No. 2008CB425704) and Basic Research Program of the Institute of Earthquake Science, CEA (No. 2014IES010102). Partial figures were generated with the GMT software (Wessel and Smith 1991).

Open Access This article is distributed under the terms of the Creative Commons Attribution License which permits any use, distribution, and reproduction in any medium, provided the original author(s) and the source are credited.

\section{References}

Allen CR, Luo Z, Qian H, Wen X, Zhou H, Huang W (1991) Field study of a highly active fault zone: the Xianshuihe fault of southwestern China. Geol Soc Am Bull 103:1178-1199

Allmendinger RW, Reilinger R, Loveless J (2007) Strain and rotation rate from GPS in Tibet, Anatolia, and the Altiplano. Tectonic. doi: $10.1029 / 2006$ TC002030

Altamimi Z, Collilieux X, Métivier L (2011) ITRF2008: an improved solution of the international terrestrial reference frame. J Geodesy 85(8):457-473

Calais E, Dong L, Wang M, Shen Z, Vergnolle M (2006) Continental deformation in Asia from a combined GPS solution. Geophys Res Lett 33:L24319. doi:10.1029/2006GL028433

Chen Z, Burchfiel BC, Liu Y, King RW, Royden LH, Tang W, Zhang X (2000) Global positioning system measurements from eastern Tibet and their implications for India/Eurasia intercontinental deformation. J Geophys Res 105(B7):16215-16227

Cheng J, Xu XW, Gan W, Ma W, Chen W, Zhang Y (2012) Block model and dynamics implication from the earthquake activities and crustal motion in the southern margin of Tibetan Plateau. Chin J Geophys 55(4):1198-1212. doi:10.6038/j.issn.00015733. 2012.04.016 (in Chinese with English abstract)

Crowell BW, Bock Y, Sandwell DT, Fialko Y (2013) Geodetic investigation into the deformation of the Salton Trough. J Geophys Res 118:1-10. doi:10.1002/jgrb.50347

Deng Q, Xu X, Yu G (1994) Characteristics of regionalization of active faults in China and their genesis. In: Department of Science and Technology, State Seismological Bureau of China ed. Active Fault research in China. Beijing, pp 1-14

Division of Earthquake Monitoring and Prediction, China Seismological Bureau (1999) Catalog of Chinese Historical Strong Earthquakes (1912-1990 $\left.M_{\mathrm{S}} \geq 4.7\right)$. Seismological Press, Beijing, p 637

Division of Earthquake Monitoring and Prediction, State Seismological Bureau (1995) Catalog of Chinese Historical Strong Earthquakes (2300 BC-1911). Seismological Press, Beijing, p 514

Dong D, Herring TA, King RW (1998) Estimating regional deformation from a combination of space and terrestrial geodetic data. J Geodesy 72(4):200-214 
Du F, Wen XZ, Zhang PZ, Wang QL (2009) Interseismic deformation across the Longmen Shan fault zone before the 2008 M8.0 Wenchuan earthquake. Chin J Geophys 52(11):2729-2738. doi:10.3969/j.issn.0001-5733 (in Chinese with English abstract)

Gan W, Zhang P, Shen ZK, Niu Z, Wang M, Wan Y, Cheng J (2007) Present-day crustal motion within the Tibetan Plateau inferred from GPS measurements. J Geophys Res 112:B08416. doi:10. 1029/2005JB004120

Herring T, King R, McClusky S (2010) GAMIT reference manual, release 10.4. Massachusetts Institute of Technology, Cambridge

Kan R, Zhang S, Yan F, Yu L (1977) Present tectonic stress and its relation to the characteristics of recent tectonic activity in southwestern China. Acta Geophsica Sinica 20(2):96-109

King RW, Bock Y (2010) Documentation for the GAMIT GPS analysis software, release 10.0, Massachusetts Institute of Technology, Cambridge

King RW, Shen F, Burchfiel BC, Royden LH, Wang E, Chen Z, Li Y (1997) Geodetic measurement of crustal motion in southwest China. Geology 25(2):179-182

Lev E, Long MD, van der Hilst RD (2006) Seismic anisotropy in Eastern Tibet from shear wave splitting reveals changes in lithospheric deformation. Earth Planet Sci Lett 251(3):293-304

Liang S, Gan W, Shen C, Xiao G, Liu J, Chen W, Zhou D (2013) Three-dimensional velocity field of present-day crustal motion of the Tibetan Plateau derived from GPS measurements. J Geophys Res 118(10):5722-5732

Liu M, Luo G, Wang H (2014) The 2013 Lushan earthquake in China tests hazard assessments. Seismol Res Lett 85(1):40-43

Meng GJ, Ren JW, Wang M, Gan WJ, Wang Q, Qiao XJ, Yang YL (2008) Crustal deformation in western Sichuan region and implications for 12 May $2008 M_{\mathrm{S}} 8.0$ earthquake. Geochem Geophys Geosyst 9(11):Q11007. doi:10.1029/2008GC002144

Michael AJ (1987) Use of focal mechanisms to determine stress-a control study. J Geophys Res 92(B1):357-368

Ren J, Xu X, Yeats RS, Zhang S (2013) Latest quaternary paleoseismology and slip rates of the Longriba fault zone, eastern Tibet: implications for fault behavior and strain partitioning. Tectonics 32(2):216-238

Shen ZK, Jackson DD, Ge BX (1996) Crustal deformation across and beyond the Los Angeles basin from geodetic measurements. J Geophys Res 101(B12):27,957-27,980

Shen ZK, Lü J, Wang M, Bürgmann R (2005) Contemporary crustal deformation around the southeast borderland of the Tibetan Plateau. J Geophys Res 110(B11):1-17

Shen ZK, Sun J, Zhang P, Wan Y, Wang M, Bürgmann R, Wang Q (2009) Slip maxima at fault junctions and rupturing of barriers during the 2008 Wenchuan earthquake. Nat Geosci 2(10): 718-724

Sol S, Meltzer A, Bürgmann R, Van der Hilst RD, King R, Chen Z, Zurek B (2007) Geodynamics of the southeastern Tibetan Plateau from seismic anisotropy and geodesy. Geology 35(6):563-566
Su Y, Qin J (2001) Strong earthquake activity and relation to regional neo-tectonic movement in Sichuan-Yunnan region. Earthq Res China 17(1):24-34

Thatcher W (2009) How the continents deform: the evidence from tectonic geodesy. Annu Rev Earth Planet Sci 37:237-262

Wang E, Burchfiel BC (2000) Late Cenozoic to Holocene deformation in southwestern Sichuan and adjacent Yunnan, China, and its role in formation of the southeastern part of the Tibetan Plateau. Geol Soc Am Bull 112(3):413-423

Wang Q, Zhang PZ, Freymueller JT, Bilham R, Larson KM, Lai XA, Chen Q (2001) Present-day crustal deformation in China constrained by global positioning system measurements. Science 294(5542):574-577

Wang CY, Mooney WD, Wang XL, Wu JP, Lou H, Wang F (2002) A study on 3-D velocity structure of crust and upper mantle in Sichuan-Yunan region, China. Acta Seismol Sinica 15(1):1-17

Wang CY, Han WB, Wu JP, Lou H, Chan WW (2007) Crustal structure beneath the eastern margin of the Tibetan Plateau and its tectonic implications. J Geophys Res. doi:10.1029/2005 JB003873

Wang Q, Qiao X, Lan Q, Jeffrey F, Yang S, Xu C, Yang Y, Tan K, You, Chen G (2011) Rupture of deep faults in the 2008 Wenchuan earthquake and uplift of the Longmen Shan. Nat Geosci 4(9):634-640

Wang C, Dai J, Zhao X, Li Y, Graham SA, He D, Meng J (2014a) Outward-growth of the Tibetan Plateau during the Cenozoic: a review. Tectonophysics 621:1-43

Wang Y, Wang F, Wang M, Shen ZK, Wan Y (2014b) Coulomb stress change and evolution induced by the 2008 Wenchuan earthquake and its delayed triggering of the $2013 M_{\mathrm{W}} 6.6$ Lushan earthquake. Seismol Res Lett 85(1):52-59

Wessel P, Smith WH (1991) Free software helps map and display data. Eos Trans Am Geophys Union 72(41):441-446

Xu ZH, Wang SY, Huang YR, Gao AJ (1989) The tectonic stress field of Chinese continent deduced from a great number of earthquakes. Chin J Geophys 32(6):636-647 (in Chinese with English abstract)

Xu X, Wen X, Zheng R, Ma W, Song F, Yu G (2003) Pattern of latest tectonic motion and its dynamics for active blocks in SichuanYunnan region. China Sci 1:152-161

Yang ZX, Waldhauser F, Chen YT, Richards PG (2005) Doubledifference relocation of earthquakes in central-western China, 1992-1999. J Seismol 9(2):241-264

Zhang PZ, Wen XZ, Shen Zk,Chen JH (2010) Oblique, high-angle, listric-reverse faulting and associated development of strain: the Wenchuan earthquake of May 12, 2008, Sichuan, China. Annu Rev Earth Planet Sci 38:353-382

Zhong JM, Cheng WZ (2006) Determinations of directions of the mean stress field in Sichuan-Yunnan region from a number of focal mechanism solutions. Acta Seismol Sinica 19:359-369 